\title{
CORRIGENDA
}

\section{The effect of functional electrical stimulation cycling on late functional improvement in patients with chronic incomplete spinal cord injury}

E Yaşar, B Yılmaz, S Göktepe and S Kesikburun

Spinal Cord (2015) 53, 900; doi:10.1038/sc.2015.47

Correction to: Spinal Cord (2015) 53, 866-869; doi:10.1038/ sc.2015.19; published online 17 February 2015

Since the publication of this article, the authors have noticed that the project funding number was absent in the acknowledgements. The correct acknowledgements are as follows:
The study was supported by The Scientific and Technological Research Council of Turkey (TUBITAK- 108S229).

The html and online PDF versions have since been amended.

\section{Treatments for erectile dysfunction in spinal cord patients: Alternatives to phosphodiesterase type 5 inhibitors? A review study}

G Lombardi, S Musco, JJ Wyndaele and G Del Popolo

Spinal Cord (2015) 53, 900; doi:10.1038/sc.2015.175

Correction to: Spinal Cord (2015) 53, 849-854; doi:10.1038/ sc.2015.116; published online 21 July 2015

Since the publication of this article, the authors have noticed an error in an author's name. The name of author G Del Popolo has been corrected above. The html and online versions have also been amended.

The authors apologise for any inconvenience caused. 